\title{
Dioscin prevents LPS-induced acute lung injury through inhibiting the TLR4/MyD88 signaling pathway via upregulation of HSP70
}

\author{
HUIQING ZENG ${ }^{1}$, LIJUAN YANG ${ }^{2},{\text { XIAOBIN } \text { ZHANG }^{1}, \text { YAN CHEN }^{1} \text { and JIANGHANG CAI }}^{1}$ \\ ${ }^{1}$ Department of Respiration Medicine, Zhongshan Hospital of Xiamen University; \\ ${ }^{2}$ Basic Medical College, Fujian Medical University, Xiamen, Fujian 361004, P.R. China
}

Received October 17, 2016; Accepted June 6, 2017

DOI: $10.3892 / \mathrm{mmr} .2018 .8667$

\begin{abstract}
Dioscin, as a type of important natural steroidal saponin, has widespread sources, primarily from the fenugreek plant, which is an important raw material in the production of synthetic steroid hormone drugs. Dioscin has anti-tumor, anti-inflammatory, antioxidant and other significant pharmacological effects with high medicinal value. The present work aimed to research the protective effect and underlying mechanisms by which dioscin prevents acute lung injury (ALI). Mice were injected with $5 \mathrm{mg} / \mathrm{kg}$ LPS to induce lung injury. Mice were treated with dioscin $(20,40$ and $60 \mathrm{mg} / \mathrm{kg})$ following LPS-induced lung injury. Treatment with dioscin significantly decreased total number of alveolar macrophages, water content of lung and total protein concentration in ALI mice. Dioscin treatment significantly suppressed the ALI-induced interleukin (IL)-1B, IL-6, tumor necrosis factor- $\alpha$, nuclear factor $(\mathrm{NF})-\kappa \mathrm{B}$, myeloperoxidase, interferon- $\gamma$ and intercellular adhesion molecule-1 activities in ALI rats. Following this, the authors identified that dioscin significantly also suppressed cyclooxygenase-2, heat shock protein 70, Toll-like receptor 4, MyD88 and NF- $\kappa$ B protein expression in ALI rats. The results suggested that dioscin prevents LPS-induced ALI through inhibiting the TLR4/MyD88 signaling pathway via upregulation of HSP70.
\end{abstract}

\section{Introduction}

Acute lung injury (ALI) is one of the clinically common emergency and severe diseases, and the infection is the major cause of the disease (1) G-bacillus infection causes acute lung injury (ALI), which is primarily because lipopolysaccharide

Correspondence to: Dr Huiqing Zeng, Department of Respiration Medicine, Zhongshan Hospital of Xiamen University, 201-209 Hubin South Road, Xiamen, Fujian 361004, P.R. China E-mail: huanyezhandi43@126.com

Key words: dioscin, acute lung injury, Toll-like receptor 4, MyD88, heat shock protein 70
(LPS) activated cells release a large amount of inflammatory factors (1). Studying LPS signal pathways and its blocking effect has important theoretical and practical significance to help understand the occurrence mechanism of ALI and could help to identify new targets of ALI treatment (2).

Gram-negative bacterial infection is the primary cause of the acute lung/acute respiratory distress syndrome (ALI/ARDS) (3). LPS, as the main pathogenic composition of Gram-negative bacteria, activates the nuclear factor- $\kappa \mathrm{B}$ $(\mathrm{NF}-\kappa \mathrm{B})$ and/or mitogen-activated protein kinase signaling molecules under the action of the receptor and regulatory proteins through the signal transduction system, resulting in the expression of various inflammatory factors (4). Such cascade amplification effect can cause the systemic inflammatory response syndrome (SIRS) and compensatory anti-inflammatory response syndrome and the excessive SIRS will develop into the multiple organ dysfunction syndromes, revealing ALI/ARDS in the lungs (5).

ALI and ARDS is one of the major diseases that causes human death (6). ALI primarily manifests in the many neutrophils of the lungs, affecting production of inflammatory mediators and lung epithelial injury (7). The host receptor recognizes the LPS, which is the most important first step to stimulate the cell signaling cascade (7). LPS can stimulate and activate a variety of cells and combine it with the CD14 receptor on the surface of the target cells. Toll-like receptor 4 (TLR4) is the proximal trans-membrane receptor of the LPS/CD14 complex, acting downstream of CD14, and transmitting the LPS signal (8). Following the pathogenic microorganisms and endogenous antigens are recognized by TLR4 on the cell surface, and the NF- $\kappa \mathrm{B}$ is activated through the MyD88-dependent or MyD88-independent signal transduction pathways, inducing the generation and release of tumor necrosis factor (TNF)- $\alpha$, interleukin (IL)-1, cyclooxygenase 2 , intercellular adhesion molecule-1 and other cell factors and chemical factors, thus leading to the neutrophil infiltration, microvascular endothelial cell injury and protein liquid leakage (9). It has been proven that CD14 and TLR4 are necessary for lipopolysaccharides to activate the immune signal transduction pathways and activate $\mathrm{NF}-\kappa \mathrm{B}$, while the activation of the latter is the common method of inflammatory reactions (10). 
Heat shock protein (HSP) is a kind of stress protein, as well as an endogenous protective substance. HSP70 is a major HSP family which is highly abundant in many organisms and markedly expressed following cell stress (11). In addition, studies have indicated that Rheum officinale serves a protective role for ALI-induced LPS, which can inhibit nitric oxide (NO) generation and inducible NO synthase activity, and reduce the activity of phospholipase A2 and platelet activating factor, thus protecting the lungs and reducing the effect of lung injury LPS-induced ALI $(12,13)$.

Dioscin, a saponin, is a naturally occurring steroid found in plants (Fig. 1). As the important raw material for the synthetic steroid hormone drugs and steroidal contraceptives, dioscin is generally used for the production of pregnenolone, progesterone, cortisol and other drugs (14). In the past few decades, the pharmacological effects of dioscin have been thoroughly studied $(15,16)$. Dioscin has an obvious antitumor effect, and it also has the function of regulating blood-lipid, anti-platelet aggregation and choleresis promotion, which is an important drug for the treatment of cardiovascular disease, encephalitis, skin diseases and tumors (16). Therefore, the aim of the present paper was to investigate the effects of dioscin against ALI and its possible mechanisms.

\section{Materials and methods}

Animal models. All animal protocols were approved by the Animal Care and Use Committee of the Zhongshan Hospital of Xiamen University (Xiamen, China). All experiments were conducted in accordance with the National Institutes of Health Guidelines for the Care and Use of Laboratory Animals. Male C57BL/6J mice (8-weeks-old; 20-22 g; n=46) were purchased from Animal Experimental Center of Xiamen University (Xiamen, China) and were maintained in a laminar-flow housing apparatus under controlled temperature $\left(22-24^{\circ} \mathrm{C}\right)$, humidity and a $12 \mathrm{~h}$ light/dark regimen. Mice had free access to food and water.

Experimental design and LPS-induced ALI model. All mice were randomly assigned to five groups: Sham $(n=6)$, LPS model $(\mathrm{n}=10), 20 \mathrm{mg} / \mathrm{kg}$ dioscin $(\mathrm{n}=10), 40 \mathrm{mg} / \mathrm{kg}$ dioscin $(\mathrm{n}=10)$ and $60 \mathrm{mg} / \mathrm{kg}$ dioscin $(\mathrm{n}=10)$. Mice were injected with $5 \mathrm{mg} / \mathrm{kg}$ LPS to induce lung injury (intrathoracic injection). Mice in the sham group were given PBS without LPS. Mice were treated with dioscin $(20,40$ and $60 \mathrm{mg} / \mathrm{kg})$ following LPS-induced lung injury. Left lung tissue samples measured using an electronic scale as wet weight (W) and heated to $70^{\circ} \mathrm{C}$ for $48 \mathrm{~h}$ to determine the dry weight (D). The water content of lung tissue was calculated with the W/D weight ratio. The left lung was lavaged with $0.5 \mathrm{ml}$ sterile saline and $2 \mathrm{ml}$ bronchoalveolar lavage fluid (BALF) was instilled. The BALF in the respiratory system was collected to detect total protein levels.

Hematoxylin and eosin staining. Right lung tissue samples were washed with ice-cold PBS and were fixed in $4 \%$ paraformaldehyde (Sinopharm Chemical Reagent Co., Ltd., Shanghai, China) for $24 \mathrm{~h}$ and embedded in paraffin. Then, the paraffin-embedded tissues samples were sliced into $5 \mu \mathrm{m}$ sections onto glass slides and stained with hematoxylin and eosin (Beyotime Institute of Biotechnology, Haimen, China). Tissues were imaged using a laser scanning confocal microscope (Nikon Eclipse TE2000-U, Nikon Corporation, Tokyo, Japan). ALI score was divided: $0=$ normal; $1=$ mild; $2=$ moderate; $3=$ severe; and calculated for a total ALI score (17).

Isolation of alveolar macrophages. Lung tissue was lavaged with $1 \mathrm{ml}$ of sterile PBS through an intratracheal catheter and BALF was collected. BALF was centrifuged at $1,000 \mathrm{xg}$ for $10 \mathrm{~min}$ at $4^{\circ} \mathrm{C}$ and pelleted cells were resuspended and cultured in a $60 \mathrm{~mm}$ culture dish in RPMI1640 supplemented with $10 \%$ fetal bovine serum, $1 \mathrm{mmol} / 1$ glutamine, $10 \mathrm{mmol} / 1$ 4-(2-hydroxyethyl)-1-piperazine ethanesulfonic acid at $37^{\circ} \mathrm{C}$ for $4 \mathrm{~h}$. The cells adhering to the bottom of dish were washed twice using PBS and total number of alveolar macrophages in BALF was calculated using a cell counting chamber.

Quantification of indicators using enzyme-linked immunosorbent assay (ELISA) kit. Mice were anaesthetized with $35 \mathrm{mg} / \mathrm{kg}$ pentobarbital sodium and the venous blood of every mouse was collected from the eye socket. Serum was collected following centrifugation at $10,000 \mathrm{x}$ for $10 \mathrm{~min}$ at $4^{\circ} \mathrm{C}$. IL- $1 \beta$ (cat no. E-EL-M0037c), IL-6 (cat no. E-EL-M0044c), TNF- $\alpha$ (cat no. E-EL-M0049c), NF-кB (cat no. E-EL-M0838c), myeloperoxidase (cat no. E-EL-H1964c), interferon- $\gamma$ (cat no. E-CL-M0046c) and ICAM-1 (cat no. E-CL-M0445c) activities were determined using a commercially available mouse ELISA kits (Elabscience, Wuhan, China).

Western blotting assay. Lung tissue samples were collected from eye socket under the condition of anesthesia and washed with ice-cold PBS. Lung tissue samples $(50 \mathrm{mg})$ were cut into pieces and immediately lysed using radioimmunoprecipitation assay lysis buffer (Beyotime Institute of Biotechnology). Protein content was determined using a bicinchoninic acid assay kit (Beyotime Institute of Biotechnology). Proteins $(50 \mu \mathrm{g})$ were subjected to $10 \%$ SDS-PAGE and then transferred to a nitrocellulose membrane (Bio-Rad Laboratories, Inc., Hercules, CA, USA). The membrane was blocked with 5\% nonfat milk in TBS with $0.1 \%$ Tween-20 for $1 \mathrm{~h}$ at $37^{\circ} \mathrm{C}$ and was incubated with anti-COX-2 (cat no. sc-7951; 1:500; Santa Cruz Biotechnology, Inc., Dallas, TX, USA), anti-TLR4 (cat no. sc-10741, 1:500; Santa Cruz Biotechnology, Inc.), anti-MyD88 (cat no. sc-11356, 1:500; Santa Cruz Biotechnology, Inc.), anti-NF-кB (cat no. sc-109, 1:500; Santa Cruz Biotechnology, Inc.), anti-HSP70 (cat no. sc-59570, 1:500; Santa Cruz Biotechnology, Inc.) and anti-GAPDH (cat no. E-AB-20079, 1:2,000; Elabscience) overnight at $4^{\circ} \mathrm{C}$. Following three washes, the membranes were incubated with goat anti-rabbit or mouse $\operatorname{IgG}$ secondary antibody conjugated with horseradish peroxidase (cat nos. sc-2004 or sc-2005; 1:5,000; Santa Cruz Biotechnology, Inc.) at room temperature for $1 \mathrm{~h}$. Membranes were visualized with enhanced chemiluminescence (Pierce; Thermo Fisher Scientific, Inc.) and bands were quantified with Image Lab software (version 3.0; Bio-Rad Laboratories, Inc.).

Statistical analysis. All values are presented as mean \pm standard error of the mean. Differences were analyzed by one-way analysis of variance with Tukey's post-hoc test, or by the 


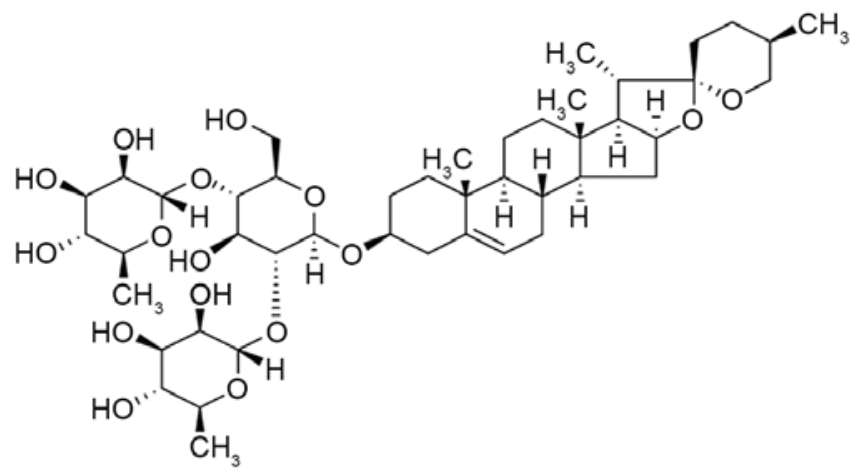

Figure 1. The constitutional formula of dioscin.

unpaired Student's t-test. $\mathrm{P}<0.05$ was considered to indicate a statistically significantly difference.

\section{Results}

Dioscin decreases lung injury score in ALI rats. As presented in Fig. 2, there was a significant increase in lung injury score of in the ALI rat model group, compared with the control group. Under these conditions, treatment with dioscin (40 and $60 \mathrm{mg} / \mathrm{kg}$ ) significantly inhibited the ALI-induced lung injury score in ALI rats, compared with the ALI rat model group (Fig. 2).

Dioscin decreases total number of alveolar macrophages, water content of lung and total protein concentration in ALI rats. Importantly, there were significant increases in total number of alveolar macrophages, water content of lung and total protein concentration in ALI rats, compared with the control group (Fig. 3). The rat in dioscin-treated (40 and $60 \mathrm{mg} / \mathrm{kg}$ ) groups demonstrated a significant reduction of these changes in lung tissue samples of ALI model rats (Fig. 3).

Dioscin decreases the activity levels of $I L-1 B, I L-6, T N F-\alpha$ and $N F-\kappa B$ in ALI rats. To determine whether the anti-inflammation effect of dioscin in ALI rats, IL-1B, IL-6, TNF- $\alpha$ and NF- $\mathrm{B}$ activity levels were measured in the current study. ALI significantly enhanced IL-1B, IL-6, TNF- $\alpha$ and NF- $\kappa$ B activity levels in ALI rats, compared with the control group (Fig. 4). Treatment with 60 and $40 \mathrm{mg} / \mathrm{kg}$ dioscin significantly suppressed the ALI-induced IL-1B, IL-6, TNF- $\alpha$ and NF- $\kappa$ B activity levels in ALI rats, compared with the ALI model rat group (Fig. 4).

Dioscin decreases MPO level in ALI rats. The authors determined the anti-inflammatory effects of dioscin in ALI rats by measuring MPO level. As presented in Fig. 5, the MPO level in all ALI rats was significantly induced, compared with the control group. However, compared with the ALI model group, treatment with 40 and $60 \mathrm{mg} / \mathrm{kg}$ dioscin was significantly different (Fig. 5).

Dioscin decreases the IFN- $\gamma$ and ICAM-1 levels in ALI rats. To further determine whether the anti-inflammatory effect of dioscin in ALI rats, IFN- $\gamma$ and TGF- $\beta 1$ levels in ALI rat were measured. As presented in Fig. 6, the activation of IFN- $\gamma$ and ICAM-1 activity levels in ALI rats was increased compared with

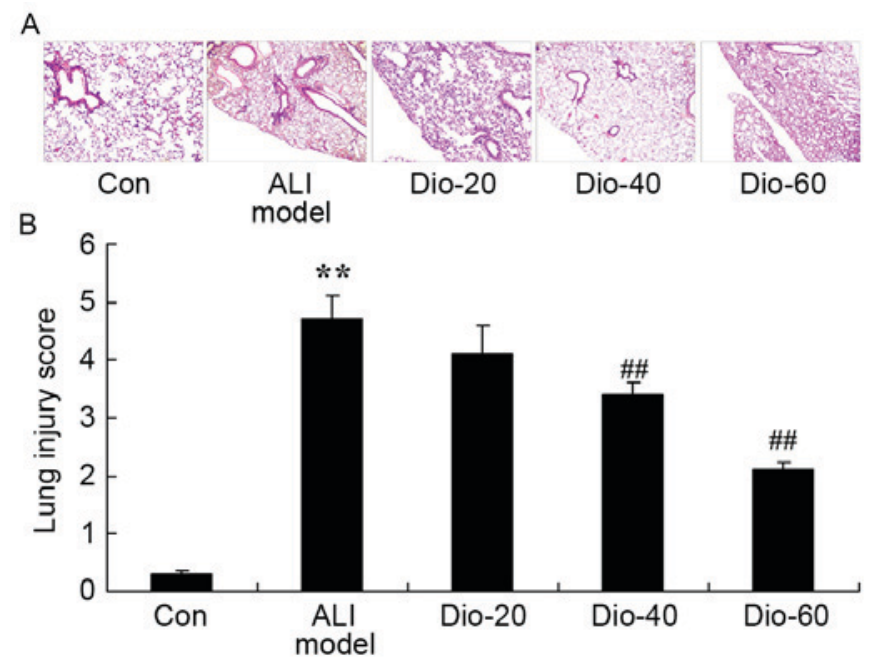

Figure 2. Dioscin decreased lung injury score in ALI rats. Dioscin prevents lung injury score using (A) hematoxylin and eosin stain (magnification, x5) and (B) statistical analysis of lung injury score in ALI rats, compared with the ALI model group. Con, control group; Dio-20, $20 \mathrm{mg} / \mathrm{kg}$ dioscin group; Dio-40, $40 \mathrm{mg} / \mathrm{kg}$ dioscin group; Dio- $60,60 \mathrm{mg} / \mathrm{kg}$ dioscin group. ${ }^{* *} \mathrm{P}<0.01$ vs. control group; ${ }^{\# \#} \mathrm{P}<0.01$ vs. ALI model group. ALI, acute lung injury.
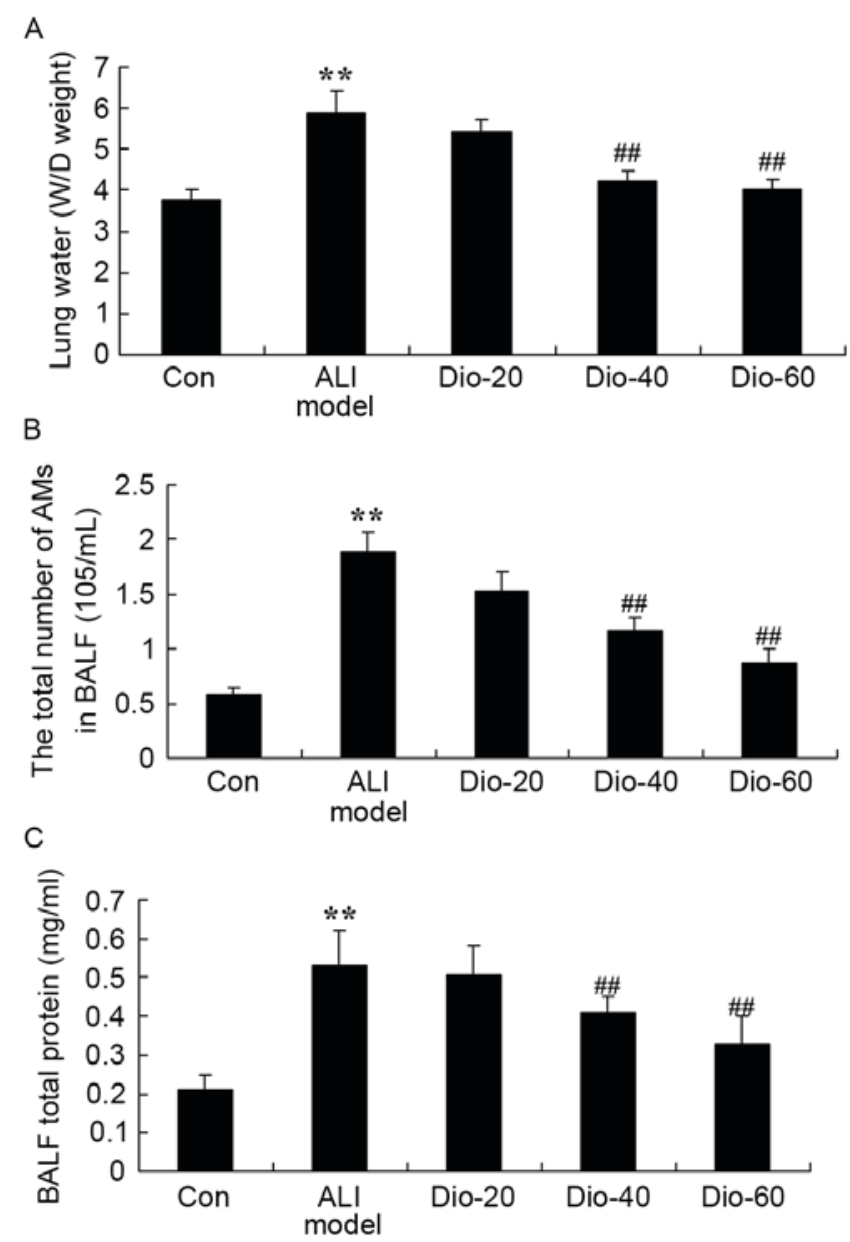

Figure 3. Dioscin decreases total number of alveolar macrophages, water content of lung and total protein concentration in ALI rats. Dioscin decreases (A) total number of alveolar macrophages, (B) water content of lung and (C) total protein concentration in ALI rats, compared with the ALI model group. Con, control group; Dio-20, $20 \mathrm{mg} / \mathrm{kg}$ dioscin group; Dio-40, $40 \mathrm{mg} / \mathrm{kg}$ dioscin group; Dio-60, $60 \mathrm{mg} / \mathrm{kg}$ dioscin group. ${ }^{* *} \mathrm{P}<0.01$ vs. control group; ${ }^{\# \#} \mathrm{P}<0.01$ vs. ALI model group. ALI, acute lung injury. 
A
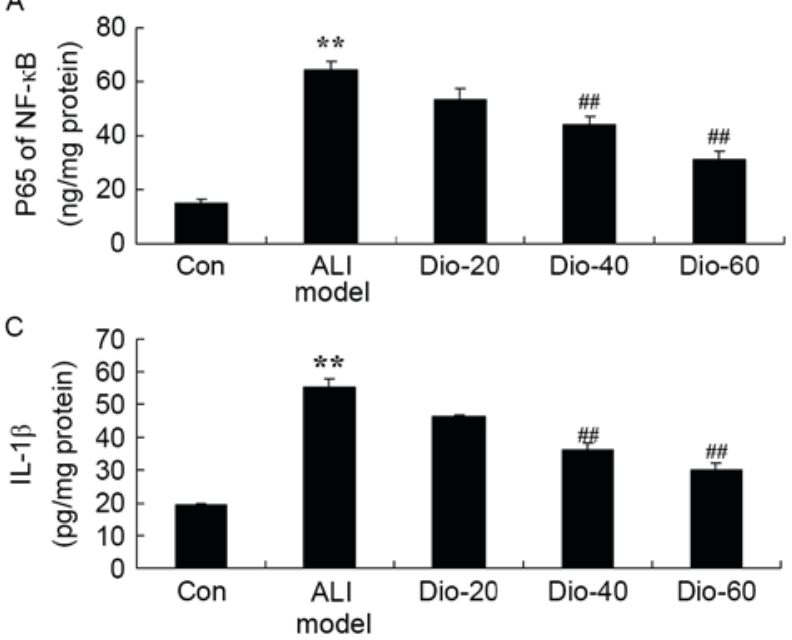

B


Figure 4. Dioscin prevents the activity levels of NF- $\kappa$ B, TNF- $\alpha$, IL-1B and IL-6 in ALI rats. Dioscin prevents the activity levels of (A) NF- $\kappa$ B, (B) TNF- $\alpha$, (C) IL-1B and (D) IL-6 in ALI rats, compared with the ALI model group. Con, control group; Dio-20, $20 \mathrm{mg} / \mathrm{kg}$ dioscin group; Dio-40, $40 \mathrm{mg} / \mathrm{kg}$ dioscin group; Dio- $60,60 \mathrm{mg} / \mathrm{kg}$ dioscin group. ${ }^{* *} \mathrm{P}<0.01$ vs. control group; ${ }^{\# \#} \mathrm{P}<0.01 \mathrm{vs}$. ALI model group. IL, interleukin; TNF- $\alpha$, tumor necrosis factor- $\alpha$; NF- $\kappa \mathrm{B}$, nuclear factor- $\kappa \mathrm{B}$; ALI, acute lung injury.

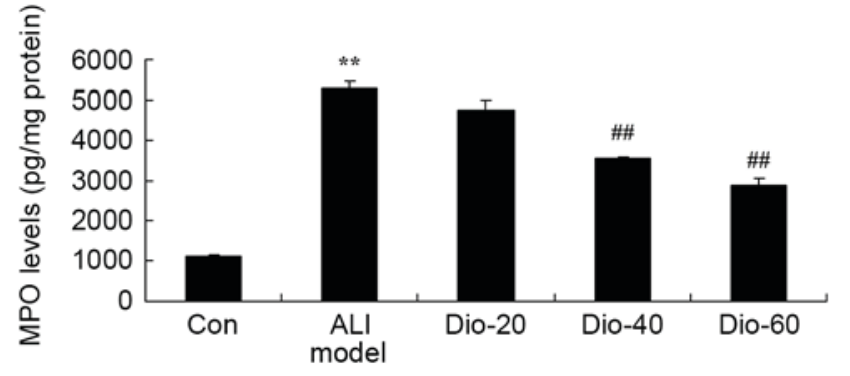

Figure 5. Dioscin decreases MPO level in ALI rats, compared with the ALI model group. Con, control group; Dio-20, $20 \mathrm{mg} / \mathrm{kg}$ dioscin group; Dio-40, $40 \mathrm{mg} / \mathrm{kg}$ dioscin group; Dio-60, $60 \mathrm{mg} / \mathrm{kg}$ dioscin group. ${ }^{* *} \mathrm{P}<0.01$ vs. control group; ${ }^{\#} \mathrm{P}<0.01$ vs. ALI model group. MPO, myeloperoxidase; ALI, acute lung injury.

the control group. In 40 and $60 \mathrm{mg} / \mathrm{kg}$ dioscin-treated groups, IFN- $\gamma$ and ICAM-1 activity levels were significantly decreased in ALI rats, compared with ALI model rat group (Fig. 6).

Dioscin decreases the COX-2 and HSP70 protein levels in ALI rats. To assess whether the anti-inflammatory effect of dioscin on COX-2 and HSP70 protein expression level in ALI rats, COX-2 protein expression level was measured using a western blotting assay. COX-2 and HSP70 protein expression levels were significantly induced by ALI, compared with the control group (Fig. 7). Meanwhile, 40 and $60 \mathrm{mg} / \mathrm{kg}$ dioscin significantly suppressed the ALI-induced COX-2 and HSP70 protein expression level in ALI rats, compared with the ALI model rat group (Fig. 7).

Dioscin decreases the TLR4, MyD88 and NF- $\kappa$ B protein levels in ALI rats. To assess whether the anti-inflammatory effect of dioscin on TLR4, MyD88 and NF- $\kappa$ B protein levels using western blotting assay. As presented in Fig. 8, ALI significantly induced TLR4, MyD88 and NF- $\kappa$ B protein expression level in ALI rats, compared with the control group (Fig. 8). 40 and $60 \mathrm{mg} / \mathrm{kg}$ dioscin significantly suppressed TLR4,
MyD88 and NF- $\mathrm{BB}$ protein levels in ALI rats, compared with the ALI model rat group (Fig. 8).

\section{Discussion}

ALI is a common severe condition, and Gram-negative bacterial infection is the major cause of the disease (18). G-bacillus is the primary pathogenic bacteria involved in the clinical infection. G-bacillus infection causes the ALI, mainly because the LPS activated cells release a large amount of inflammatory factors, so LPS is important to mediate SIRS, as well as multiple organ dysfunction syndrome (19). The alveolar macrophages are the first defense line in the respiratory tract, and are also the main effector cell of LPS (19). Studying the LPS signaling pathways and its blocking effect has important theoretical and practical significance to help understand the occurrence mechanism of ALI and look for the new target in ALI treatment (5). In the present work, dioscin significantly inhibited ALI score, total number of alveolar macrophages, water content of lung and total protein concentration in ALI rats. Tao et al (14) suggested that dioscin attenuates hepatic ischemia-reperfusion injury via anti-inflammation and apoptosis in rats.

TLR4, as the receptor of lipopolysaccharides (the primary component of the outer wall of Gram-negative bacteria cell), has an important role in the inflammatory response (20). Besides LPS, other endogenous ligands can also activate the TLR4 receptor, such as the high-speed transfer protein B1, HSP70, and other factors released from dead or injured cells that can activate TLR4 and NF- $\mathrm{BB}$, leading to the release of inflammatory factors TNF- $\alpha$, IL-1 and IL-6 (11). In the current study, the authors demonstrated that dioscin significantly suppressed the ALI-induced IL-1B, IL-6, TNF- $\alpha$ and NF- $\kappa$ B activity, inhibited MPO, IFN- $\gamma$ and ICAM-1 activity and decreased COX-2 protein expression in ALI model rats. Wu et al (21) reported that dioscin suppresses TNF- $\alpha$-induced vascular cell adhesion protein-1, ICAM-1 and the NF- $\kappa$ B pathway.

The activation of TLR4 leads the adaptor protein containing the TIR structure domain in the cells, such as 

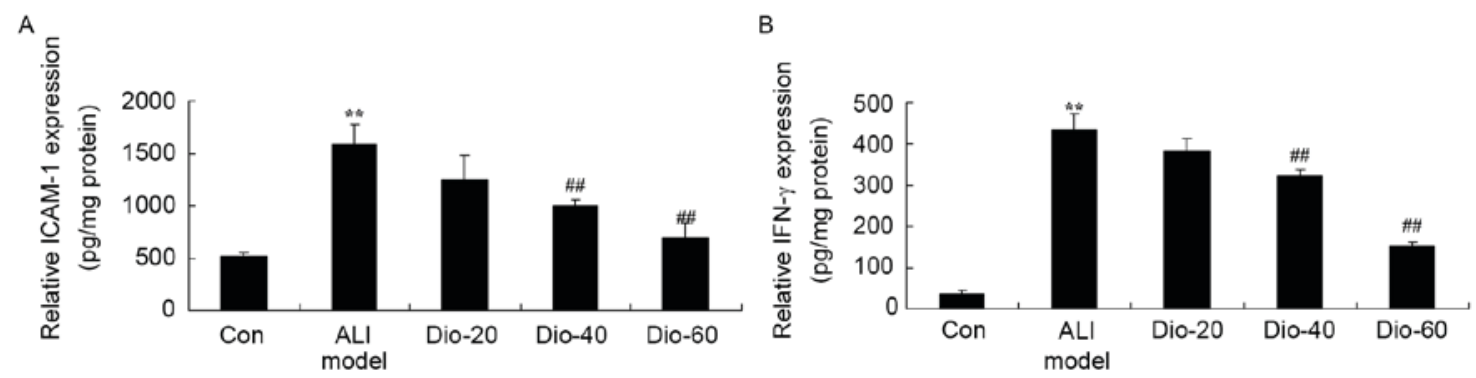

Figure 6. Dioscin decreases the IFN- $\gamma$ and ICAM-1 levels in ALI rats. Dioscin prevents (A) ICAM-1 and the (B) IFN- $\gamma$ levels in ALI rats, compared with the ALI model group. Con, control group; Dio-20, $20 \mathrm{mg} / \mathrm{kg}$ dioscin group; Dio-40, $40 \mathrm{mg} / \mathrm{kg}$ dioscin group; Dio- $60,60 \mathrm{mg} / \mathrm{kg}$ dioscin group. ** P<0.01 vs. control group; ${ }^{\# \#} \mathrm{P}<0.01$ vs. ALI model group. IFN- $\gamma$, interferon- $\gamma ;$ ICAM, intercellular adhesion molecule-1; ALI, acute lung injury.
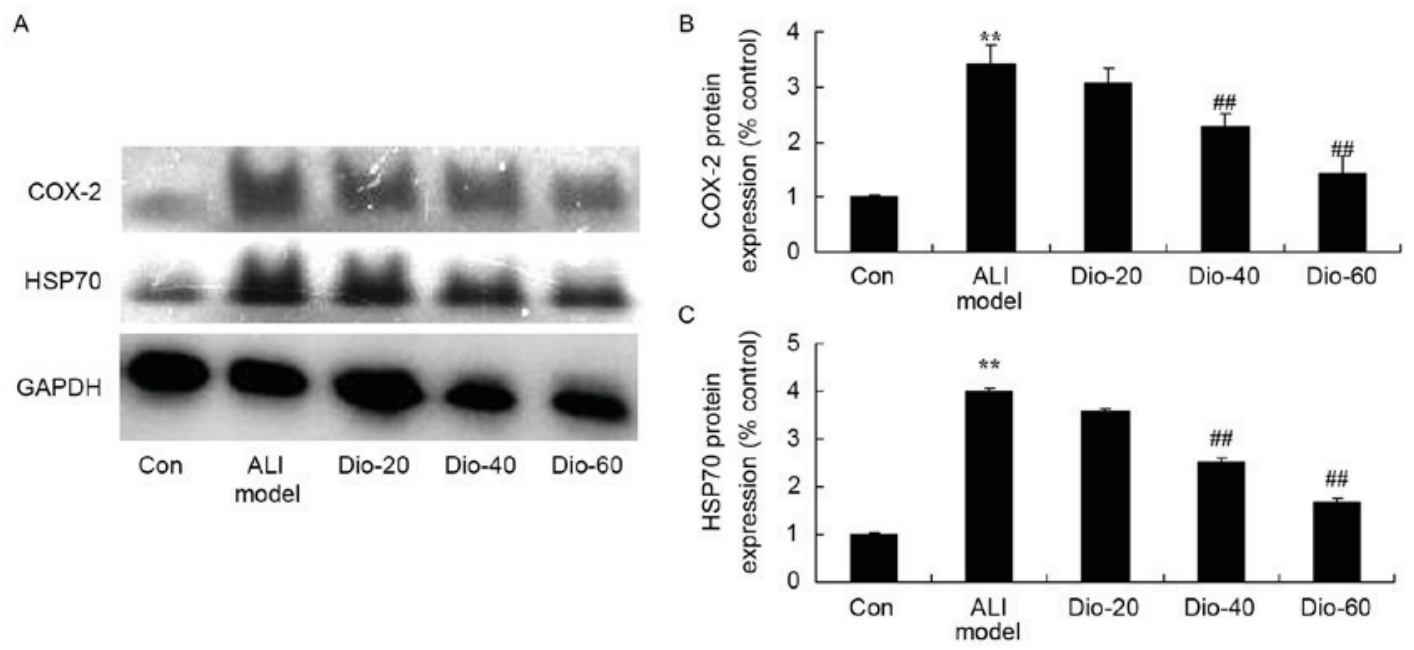

Figure 7. Dioscin decreases the COX-2 and HSP70 protein levels in ALI rats, compared with the ALI model group. Dioscin prevents the (A) COX-2 and HSP70 protein levels by western blotting assays and (B and C) statistical analysis of COX-2 and HSP70 protein levels in ALI rats. Con, control group; Dio-20, $20 \mathrm{mg} / \mathrm{kg}$ dioscin group; Dio-40, $40 \mathrm{mg} / \mathrm{kg}$ dioscin group; Dio- $60,60 \mathrm{mg} / \mathrm{kg}$ dioscin group. ${ }^{* *} \mathrm{P}<0.01 \mathrm{vs}$. control group; ${ }^{\# /} \mathrm{P}<0.01 \mathrm{vs}$. ALI model group. COX-2, cyclooxygenase-2; HSP70, heat shock protein 70; ALI, acute lung injury.
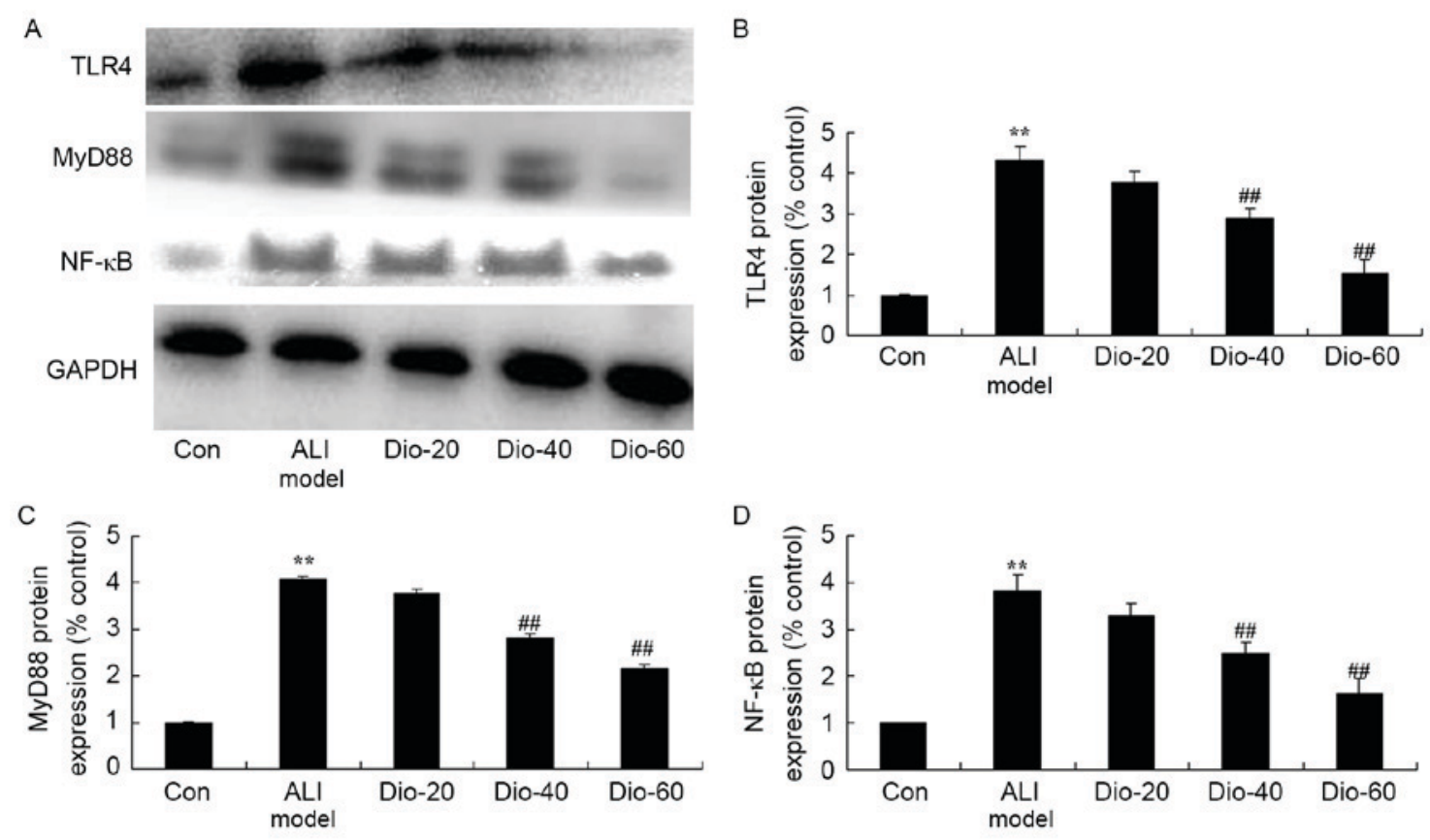

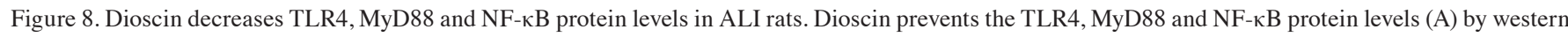
blotting assays and (B-D) statistical analysis of COX-2 and HSP70 protein levels in ALI rats. Con, control group; Dio-20, $20 \mathrm{mg} / \mathrm{kg}$ dioscin group; Dio-40, $40 \mathrm{mg} / \mathrm{kg}$ dioscin group; Dio-60, $60 \mathrm{mg} / \mathrm{kg}$ dioscin group. ${ }^{* *} \mathrm{P}<0.01$ vs. control group; ${ }^{\# \#} \mathrm{P}<0.01$ vs. ALI model group. TLR4, Toll-like receptor 4 ; NF-kB, nuclear factor-kB; ALI, acute lung injury; COX-2, cyclooxygenase-2; HSP70, heat shock protein 70. 
MyD88, to the TLR4 intracellular structure domain (10). Thus, TLR4-mediated signaling pathways can be divided into the MyD88-dependent and MyD88-independent ones (22). MyD88 was originally identified as the members of the 12 myeloid differentiation initial response genes. MyD88, as the adaptor protein, can mediate the signal transduction of 10 TLRs families (23). MyD88-dependent signaling pathway may be involved in the injury caused by ischemia reperfusion, aggravating the organ damage. Some in vivo tests have proved that the TLR4-mediated MyD88 signaling pathway induces the immune response in ALI (24). In the present work, dioscin significantly suppressed TLR4, MyD88 and NF- $\mathrm{B}$ protein levels in ALI. Liu et al (25) exhibited that dioscin alleviates alcoholic liver fibrosis through the TLR4/MyD88/NF- $\mathrm{B}$ signaling pathway in hepatic stellate cell activation. These data demonstrated that the anti-inflammatory effect of dioscin on ALI through suppression of the TLR4/MyD88/NF- $\kappa \mathrm{B}$ signaling pathway.

There has been thorough research on the TLR4-mediated MyD88 signaling pathways caused by pathogenic microorganisms, but the TLR4-activated ligand, caused by damage, requires further research (24). It is reported that the endogenous ligand HSP70 and HMGBI can activate TLR2 and TLR4 in the case of no pathogens, causing inflammation (11). HSP is a stress protein, as well as an endogenous protective material, and according to the molecular weight, it can be divided into HSP100, HSP90, HSP70, HSP60, HSP40 and small molecular weight HSP (26). HSP70 is a highly conserved protein expressed in the majority of organisms. It is highly expressed following cellular stress events and exerts protective effects (27). In addition, it is worth mentioning that inducing and increasing the expression of HSP70 in lung tissue through the thermal pretreatment, drug or gene transfer methods can reduce the animal's ALI inflammatory reaction, apoptosis of lung tissue and pulmonary edema. Therefore, this improves the blood oxygen content, reducing the mortality of animals, so that HSP has a protective effect on ALI $(27,28)$. The current results indicated that dioscin significantly suppressed the ALI-induced HSP70 protein expression level in ALI. Qi et al (29) suggested that dioscin inhibits renal ischemia/reperfusion injury via upregulation of HSP70.

In conclusion, the present results indicated that dioscin significantly inhibited ALI-induced lung injury score, total number of alveolar macrophages, water content of lung and total protein concentration in ALI rats via the inhibition of inflammation, inhibiting the TLR4/MyD88 signaling pathway via upregulation of HSP70. The findings suggested the therapeutic potential of dioscin for ALI.

\section{Acknowledgements}

Not applicable.

\section{Funding}

No funding was received.

\section{Availability of data and materials}

The analyzed datasets generated during the study are available from the corresponding author on reasonable request.

\section{Author's contributions}

HZ, LY, XZ, YC and JC performed the animal and cell experiments and analyzed the data. HZ designed the experiments and wrote the manuscript. HZ and LY performed reverse transcription-quantitative polymerase chain reaction and western blot analyses.

\section{Ethics approval and consent to participate}

All animal protocols were approved by the Animal Care and Use Committee of the Zhongshan Hospital of Xiamen University. All experiments were conducted in accordance with the National Institutes of Health Guidelines for the Care and Use of Laboratory Animals.

\section{Consent for publication}

Not applicable.

\section{Competing interests}

The authors declare that they have no competing interests.

\section{References}

1. Krupa A, Fol M, Rahman M, Stokes KY, Florence JM, Leskov IL, Khoretonenko MV, Matthay MA, Liu KD, Calfee CS, et al: Silencing Bruton's tyrosine kinase in alveolar neutrophils protects mice from LPS/immune complex-induced acute lung injury. Am J Physiol Lung Cell Mol Physiol 307: L435-L448, 2014.

2. Wang Q, Wang J, Hu M, Yang Y, Guo L, Xu J, Lei C, Jiao Y and $\mathrm{Xu}$ J: Uncoupling protein 2 increases susceptibility to lipopolysaccharide-induced acute lung injury in mice. Mediators Inflamm 2016: 9154230, 2016.

3. Bohman JK, Vogt MN and Hyder JA: Retrospective report of contraindications to extracorporeal membrane oxygenation (ECMO) among adults with acute respiratory distress syndrome (ARDS). Heart Lung 45: 227-231, 2016.

4. Xu X, Liu N, Zhang YX, Cao J, Wu D, Peng Q, Wang HB and Sun WC: The protective effects of HJB-1, a derivative of 17-Hydroxy-Jolkinolide B, on LPS-Induced acute distress respiratory syndrome mice. Molecules 21: 77, 2016.

5. Rafat N, Dacho C, Kowanetz G, Betzen C, Tönshoff B, Yard B and Beck G: Bone marrow-derived progenitor cells attenuate inflammation in lipopolysaccharide-induced acute respiratory distress syndrome. BMC Res Notes 7: 613, 2014.

6. Petroni RC, Biselli PJ, de Lima TM, Theobaldo MC, Caldini ET, Pimentel RN, Barbeiro HV, Kubo SA, Velasco IT and Soriano FG: Hypertonic saline $(\mathrm{NaCl} 7.5 \%)$ reduces LPS-Induced acute lung Injury in rats. Inflammation 38: 2026-2035, 2015.

7. McKallip RJ, Ban $\mathrm{H}$ and Uchakina ON: Treatment with the hyaluronic Acid synthesis inhibitor 4-methylumbelliferone suppresses LPS-induced lung inflammation. Inflammation 38: 1250-1259, 2015

8. Krupa A,FudalaR,FlorenceJM,TuckerT,AllenTC,StandifordTJ, Luchowski R, Fol M, Rahman M, Gryczynski Z, et al: Bruton's tyrosine kinase mediates Fc $\gamma$ RIIa/Toll-like receptor-4 receptor crosstalk in human neutrophils. Am J Respir Cell Mol Biol 48: 240-249, 2013.

9. Han LP, Li CJ, Sun B, Xie Y, Guan Y, Ma ZJ and Chen LM: Protective effects of celastrol on diabetic liver injury via TLR4/MyD88/NF- $\mathrm{BB}$ signaling pathway in Type 2 diabetic rats. J Diabetes Res 2016: 2641248, 2016.

10. Chen S, Yuan J, Yao S, Jin Y, Chen G, Tian W, Xi J, Xu Z, Weng D and Chen J: Lipopolysaccharides may aggravate apoptosis through accumulation of autophagosomes in alveolar macrophages of human silicosis. Autophagy 11: 2346-2357, 2015. 
11. Zhang Y, Shan P, Srivastava A, Jiang G, Zhang X and Lee PJ: An endothelial Hsp70-TLR4 axis limits Nox3 expression and protects against oxidant injury in lungs. Antioxid Redox Signal 24: 991-1012, 2016.

12. Lunova M, Zizer E, Kucukoglu O, Schwarz C, Dillmann WH, Wagner M and Strnad P: Hsp72 overexpression accelerates the recovery from caerulein-induced pancreatitis. PLoS One 7: e39972, 2012.

13. Aschkenasy G, Bromberg Z, Raj N, Deutschman CS and Weiss YG: Enhanced Hsp70 expression protects against acute lung injury by modulating apoptotic pathways. PLoS One 6 : e26956, 2011.

14. Tao X, Wan X, Xu Y, Xu L, Qi Y, Yin L, Han X, Lin Y and Peng J: Dioscin attenuates hepatic ischemia-reperfusion injury in rats through inhibition of oxidative-nitrative stress, inflammation and apoptosis. Transplantation 98: 604-611, 2014.

15. Zhao X, Xu L, Zheng L, Yin L, Qi Y, Han X, Xu Y and Peng J: Potent effects of dioscin against gastric cancer in vitro and in vivo. Phytomedicine 23: 274-282, 2016.

16. Qu X, Zhai Z, Liu X, Li H, Ouyang Z, Wu C, Liu G, Fan Q Tang T, Qin A and Dai K: Dioscin inhibits osteoclast differentiation and bone resorption though down-regulating the Akt signaling cascades. Biochem Biophys Res Commun 443: 658-665, 2014

17. Wu DD, Pan PH, Liu B, Su XL, Zhang LM, Tan HY, Cao Z, Zhou ZR, Li HT, Li HS, et al: Inhibition of alveolar macrophage pyroptosis reduces Lipopolysaccharide-induced acute lung injury in mice. Chin Med J (Engl) 128: 2638-2645, 2015.

18. Jones HD, Crother TR, Gonzalez-Villalobos RA, Jupelli M, Chen S, Dagvadorj J, Arditi M and Shimada K: The NLRP3 inflammasome is required for the development of hypoxemia in LPS/mechanical ventilation acute lung injury. Am J Respir Cell Mol Biol 50: 270-280, 2014.

19. Haitsma JJ, Lachmann B and Papadakos PJ: Additives in intravenous anesthesia modulate pulmonary inflammation in a model of LPS-induced respiratory distress. Acta Anaesthesiol Scand 53: 176-182, 2009.
20. Takahashi M, Chen-Yoshikawa TF, Menju T, Ohata K, Kondo T, Motoyama H, Hijiya K, Aoyama A and Date H: Inhibition of Toll-like receptor 4 signaling ameliorates lung ischemia-reperfusion injury in acute hyperglycemic conditions. J Heart Lung Transplant 35: 815-822, 2016.

21. Wu S, Xu H, Peng J, Wang C, Jin Y, Liu K, Sun H and Qin J: Potent anti-inflammatory effect of dioscin mediated by suppression of TNF- $\alpha$-induced VCAM-1, ICAM-1and EL expression via the NF- $\kappa$ B pathway. Biochimie 110: 62-72, 2015.

22. Zhang Z, Chen N, Liu JB, Wu JB, Zhang J, Zhang Y and Jiang X Protective effect of resveratrol against acute lung injury induced by lipopolysaccharide via inhibiting the myd88-dependent Toll-like receptor 4 signaling pathway. Mol Med Rep 10: 101-106, 2014

23. Wan Q, Wang H, Han X, Lin Y, Yang Y, Gu L, Zhao J, Wang L, Huang L, Li Y and Yang Y: Baicalin inhibits TLR7/MYD88 signaling pathway activation to suppress lung inflammation in mice infected with influenza A virus. Biomed Rep 2: 437-441, 2014.

24. Jiang Q, Yi M, Guo Q, Wang C, Wang H, Meng S, Liu C, Fu Y, Ji H and Chen T: Protective effects of polydatin on lipopolysaccharideinduced acute lung injury through TLR4-MyD88-NF- $\mathrm{B}$ pathway. Int Immunopharmacol 29: 370-376, 2015.

25. Liu M, Xu Y, Han X, Yin L, Xu L, Qi Y, Zhao Y, Liu K and Peng J: Dioscin alleviates alcoholic liver fibrosis by attenuating hepatic stellate cell activation via the TLR4/MyD88/NF- $\kappa \mathrm{B}$ signaling pathway. Sci Rep 5: 18038, 2015.

26. Lyons MM, Raj NN, Chittams JL, Kilpatrick L and Deutschman CS: TAT-HSP70 attenuates experimental lung injury. Shock 43: 582-588, 2015.

27. Zhang ZJ, Zhou CY, Luo YJ and Xiong HW: Expression of heat shock protein 70 in lung tissues of acute paraquat poisoned rats and intervention of ulinastatin. World J Emerg Med 1: 229-233, 2010.

28. Lin HJ, Wang CT, Niu KC, Gao C, Li Z, Lin MT and Chang CP: Hypobaric hypoxia preconditioning attenuates acute lung injury during high-altitude exposure in rats via up-regulating heat-shock protein 70. Clin Sci (Lond) 121: 223-231, 2011.

29. Qi M, Zheng L, Qi Y, Han X, Xu Y, Xu L, Yin L, Wang C, Zhao Y, Sun H, et al: Dioscin attenuates renal ischemia/reperfusion injury by inhibiting the TLR4/MyD88 signaling pathway via up-regulation of HSP70. Pharmacol Res 100: 341-352, 2015. 